\title{
DILEMAS PESSOAIS NO TRABALHO IMATERIAL BANCÁRIO
} PERSONAL DILEMMAS IN THE BANKING IMMATERIAL LABOUR

\author{
Carmem Lígia Iochins Grisci \\ Universidade Federal do Rio Grande do Sul, Porto Alegre, Brasil \\ Priscila Daniel Scalco \\ Universidade de Londres, Londres, Reino Unido \\ Gabriela Elnecave Kruter \\ Universidade Federal do Rio Grande do Sul, Porto Alegre, Brasil
}

\section{RESUMO}

Visando destacar e analisar a vivência de dilemas pessoais ante a lógica do trabalho imaterial bancário, a presente pesquisa exploratória de orientação qualitativa aliou o suporte teórico oferecido, principalmente, por Bauman, Sennett e Gaulejac ao campo empírico referente ao trabalho bancário. A coleta de dados deu-se por meio da realização de entrevistas individuais semiestruturadas e de grupos focais, que somaram um total de 38 sujeitos da pesquisa. Analisados à luz da literatura pertinente, os resultados indicam que a vivência de dilemas pessoais no trabalho imaterial bancário está relacionada ao medo da incompetência e estigma de perdedor, ao nomadismo involuntário, à captura e dominação do tempo de vida, à corrida individualizada para o mérito, ao medo da estagnação profissional e à saúde na precarização das relações de trabalho.

Palavras-chave: trabalho imaterial; trabalho bancário; dilemas pessoais.

\begin{abstract}
The present qualitative exploratory research aims to analyze the experience of personal dilemmas in the context of banking immaterial labor. The theoretical support is mainly offered by Bauman, Sennett and Gaulejac. The data collection method used was semi-structured individual interviews and two focus groups, all counting 38 participants. The results were analyzed according to the pertinent literature and they indicate that personal dilemmas in the banking work are related to fear of incompetence stigma; to the involuntary nomadism; to the fact that work captures and dominates time after work; to competition for merit; fear of professional stagnation; and to health conditions under precarious labor relations.
\end{abstract}

Keywords: immaterial labor; banking labor; personal dilemmas.

\section{Introdução}

Dentre as questões que surgem no cotidiano do trabalho, algumas evidenciam parte dos desdobramentos vividos pelo trabalhador nas relações de trabalho contemporâneas, algo que pode infligir tensão e sofrimento. Como lidar com um cenário onde o imperativo das metas aumenta ao passo que o tempo para que se realizem é cada vez mais exíguo? Como lidar com constrangimentos advindos da avaliação de que é preciso fazer concessões e mostrar disponibilidade ao trabalho como uma autodisciplina desenvolvida? Como conviver com as demandas cada vez mais exigentes e com a ideia de vulnerabilidade e medo de se tornar obsoleto e de ser excluído? Lazzarato e Negri (2001), Bauman (2001, 2007a, 2007b), Sennett (2001, 2006) e Gaulejac (2007) mostram-se importantes a essa temática, que visa a problematizar os atuais modos de trabalhar e de gestão possibilitando direcionar o olhar aos dilemas pessoais contemporâneos. De acordo com Lazzarato e Negri (2001), o trabalho imaterial configura-se numa nova relação produção-consumo ao se colocar no centro da produção, por meio de qualidades inerentes ao trabalhador, que extrapolam o campo do saber técnico. E decorre de uma ruptura dos limites que outrora separavam o trabalho das demais esferas da vida. As atuais formas de estruturar e organizar o trabalho bancário, em especial, via o abandono de rígidos padrões espaços-temporais, a utilização de sutis modos de controle e a adoção de novas tecnologias da informação e comunicação, permi- 
tem tomá-lo sob a noção de trabalho imaterial (Grisci, 2008). Frente a situações nem sempre prescritas ou conhecidas com antecipação, o exercício do trabalho imaterial bancário mobiliza dimensões subjetivas por parte dos trabalhadores, em especial no que se refere à experiência de vida adquirida, às capacidades de discernimento, auto-organização, comunicação e relacionamento, no sentido de oferecer aos consumidores dos serviços bancários sensação de confiança e segurança relativa aos negócios estabelecidos com o banco. O trabalho imaterial "não se reproduz (e não reproduz a sociedade) na forma de exploração, mas na forma de reprodução da subjetividade" (Lazzarato \& Negri, 2001, p.30). Ao ser demandado na forma de produção, e compreendido como fator de rentabilidade para as empresas, pode-se afirmar juntamente com Pelbart (2000, p.37) que "o trabalho precisa da vida como nunca, e seu produto afeta a vida numa escala sem precedentes". Nesse sentido, refletir acerca da vivência de dilemas relativos ao trabalho equivale a refletir sobre a vivência de dilemas relativos à vida como um todo.

Por dilema pessoal compreende-se, em geral, a vivência de uma situação embaraçosa, que aponta saídas difíceis ou penosas, frente à qual os sujeitos se veem entre a cruz e a espada, sem possibilidade de escolha satisfatória. Além disso, "a responsabilidade em resolver os dilemas gerados por circunstâncias voláteis e constantemente instáveis é jogada sobre os ombros dos indivíduos - dos quais se espera que sejam 'free-choosers' e suportem plenamente as conseqüências de suas escolhas" (Bauman, 2007a, p.10). Ainda nas palavras de Bauman (2007b, p.142):

o ambiente líquido e de fluxo rápido privilegia os que podem viajar com velocidade; se as novas circunstâncias exigem movimento rápido e um recomeço a partir do zero, os compromissos de longo prazo e quaisquer laços difíceis de desatar podem revelar-se um fardo incômodo - um peso a ser jogado ao mar. Não há, então, uma boa escolha. Não se pode ficar com a torta e comê-la - mas é exatamente isso que você é pressionado a fazer pelo ambiente em que tenta compor sua vida. Qualquer escolha que você faça, está arranjando confusão.

O presente estudo alia o suporte teórico oferecido, principalmente, por Lazzarato e Negri (2001), Bauman (2001, 2007a, 2007b), Sennett $(2001,2006)$ e Gaulejac (2007) ao campo empírico que toma o trabalhador bancário como categoria exposta à lógica de trabalho compreendida como fonte de dilemas representativos da sociedade contemporânea. Nas seções a seguir, apresentam-se a base de sustentação teórica do estudo, os procedimentos metodológicos adotados e os resultados e sua análise. Por fim, tecem-se as considerações finais.

\section{Referencial teórico}

\section{Modos de Gestão no Trabalho Imaterial Bancário e Dilemas Pessoais}

Os atuais modos de gestão, condizentes com a lógica do trabalho imaterial, primam pelo incremento da criatividade e da engenhosidade dos trabalhadores, de suas capacidades de cooperação, gerenciamento de informação e de tomada de decisão de modo a usufruí-las como fator de produtividade e competitividade entre as empresas (Grisci, 2006).

Bauman (2001) observa que as mudanças na relação de produção, a começar pelas novidades tecnológicas, a flexibilização da legislação trabalhista e a mobilidade do capital, modificaram irremediavelmente o trabalho e as demais relações sociais. Tal liquefação da realidade pode ter posto por terra referências que organizavam o mundo tal qual ele era conhecido, ter derrubado instituições e transformado os valores compartilhados socialmente. $\mathrm{O}$ trabalho, neste entorno, teria passado a se apoiar em tênues pilares, que indicariam a flexibilização dos vínculos e das relações cada vez mais fragilizadas. O modelo atual de gestão promove essa flexibilização, e impõe a mobilidade como norma, pois "o homem flexível substitui o homem de profissão. A profissão, que era o elemento fundador da identidade profissional, não é mais o elemento persistente das trajetórias" (Gaulejac, 2007, p. 244).

No que se refere aos modos de gestão, a rentabilização da fluidez dos processos e das flexibilizações seria um dos fios condutores das organizações e, por consequência, afetaria a vida daqueles que nelas trabalham. De acordo com Sennett (2001), a capacidade de se estar aberto a constantes mudanças e a elas rapidamente se adaptar, dificultam a construção de laços de confiança e ajuda mútua, comprometendo a formação do caráter.

Tal percepção acentua-se à medida que os ambientes de trabalho tornam-se cada vez mais competitivos seguindo as exigências de um capitalismo de acumulação flexível e volátil, onde o tempo de giro de produção e consumo é cada vez menor e, portanto, exige trabalhadores capazes de reagir diante de novas demandas (Harvey, 1993). Esse cenário propicia a exaltação do "eu, sociedade anônima" a sentenciar, como tão bem observou Gaulejac (2007, p.144), que "Cada um deve aprender a gerir sua vida e gerir a si mesmo". Trata-se da "cultura do desempenho" (p.145) que compele o sujeito à busca, não só de ser o melhor, mas também de ser o primeiro.

As práticas gerencialistas que reforçam tais características (Gaulejac, 2007), são consonantes aos modos de trabalho flexibilizados que demandam do sujeito a mobilização de suas capacidades em prol da organização. Dessa forma, argumenta Gaulejac, (2007, p.177), 
"a gestão gerencialista gera uma rentabilização do humano, e cada indivíduo deve tornar-se o gestionário de sua vida, fixar-se objetivos, avaliar seus desempenhos, tornar seu tempo rentável". Tais práticas, associadas à percepção de que a passagem do tempo e a implementação de mudanças ocorrem de modo acelerado, podem dar margem ao surgimento de dilemas pessoais relativos à esfera do trabalho e da gestão.

Os atuais modos de gestão, no que tange ao tempo, permitem ao sujeito certa sensação de autonomia, no entanto, o que se verificaria é uma extensão do controle da instituição sobre o sujeito, já que este acaba ampliando seu contato com a empresa através do aparato tecnológico disponível. Passível de ser contatado em qualquer hora e lugar, o sujeito contemporâneo confirma que "não existe mais aqui, tudo é agora", conforme aponta Virilio (1999, p.121).

No que tange ao tempo ${ }^{1}$ e sua relação com os dilemas contemporâneos pode-se argumentar o fato de que as relações de trabalho estão calcadas em uma lógica que elimina os ancoradouros e desconsidera as trajetórias, fazendo com que a capacidade de se abrir mão e permitir que o passado fique para trás tornem-se fundamentais à medida que migrar de tarefa em tarefa, de emprego em emprego, de um lugar para o outro são uma exigência na busca de colocação profissional (Sennett, 2001, 2006), de modo que "aquele que resiste é catalogado como não empregável" (Gaulejac, 2007, p. 241).

Nesse sentido, restaria ao sujeito esforçar-se para fugir do estigma de 'perdedor' e permanecer na corrida, temendo, inclusive, ser "pego tirando uma soneca" (Bauman, 2007b, p.8). O constante estado de alerta extrapolaria as relações profissionais e se estenderia à vida como um todo, permitindo a invasão do privado pela atividade em uma espécie de "colonização do espaço e do tempo pessoal" (Gaulejac, 2007, p.180).

De acordo com Sennett (2001), o fracasso seria o tabu da modernidade. Nesse sentido, complementa Bauman (2001, p.76), a atual exigência de que cada sujeito seja gestor de si sugere "que a redenção e a condenação são produzidas pelo indivíduo e somente por ele - o resultado do que o agente livre fez livremente de sua vida". Sendo assim, seria o responsável por cultivar méritos e reparar os fracassos (Bauman, 2007b). Como consequência, o sujeito assumiria a necessidade de controlar seu próprio trabalho, sua produtividade, mesmo sabendo que, muitas vezes, a origem de certas falhas não se dá por razões passíveis de serem controladas. Frente a isso, instala-se a tensão, o sofrimento e o medo da incompetência e de não estar à altura de determinadas posições (Dejours, 2001). Isso corrobora o que Bauman (2007b) diz a respeito da vida líquida, que é vivida sob a condição de mudanças constantes, onde quase que instantaneamente os ativos se transformam em passivos.
Desta forma, a lógica vigente aponta o sujeito como senhor de si, incumbido de responsabilizar-se por suas escolhas e estilo de vida e, assim, "resolver os dilemas gerados por circunstâncias voláteis e constantemente instáveis" (Bauman, 2007a, p.10). Nessa perspectiva, resta ao trabalhador se flexibilizar e se adaptar aos novos cenários. Essa adaptação implica frequentemente experimentação de sofrimento psíquico. $\mathrm{O}$ trabalho da contemporaneidade, da modernidade líquida, é o trabalho imaterial, que veio a redefinir o próprio trabalhador, uma vez que "o capitalismo contemporâneo não organiza mais o 'tempo de trabalho', mas o 'tempo de vida"" (Lazzarato \& Negri, 2001, p.88). Assim, as transformações do trabalho e da gestão, e a vida líquida, conduzem à ideia de que os dilemas pessoais contemporâneos configuram-se nos atuais modos de trabalhar e de gestão atravessados pela noção de trabalho imaterial, que engendra novas formas de produção e, consequentemente, novas formas de subjetivação ou produção de estilos de vida ou modos de existência.

\section{Procedimentos metodológicos}

A pesquisa exploratória de orientação qualitativa propicia a abordagem de um tema com pouco conhecimento sistematizado (Vergara, 2000), o que se considerou apropriado ao caso dos dilemas pessoais no trabalho imaterial bancário. Ao proporcionar maior familiaridade com o problema, o estudo exploratório permitiu abordarem-se categorias como trabalho imaterial, tempo, medo e sofrimento no trabalho sob perspectivas que, inclusive, poderão vir a ser aprofundadas em estudos posteriores.

Os 38 sujeitos participantes desta pesquisa são trabalhadores bancários de diferentes bancos públicos e privados. Eles somam 25 homens e 13 mulheres. Com idade entre 25 e 55 anos, são majoritariamente casados, e apresentam escolaridade de nível superior completo e incompleto. Ocupam cargos de técnico bancário, auditor, caixa, gerente de conta e gerente geral. Do total de 38 sujeitos, são transpostas na apresentação e análise dos resultados, as falas daqueles 19 que melhor exemplificaram uma ideia compartilhada por vários. Os sujeitos mencionados no presente artigo receberam nomes fictícios. Gabriel (26a, público A, auditor), Ronaldo (50a, público B, gerente geral), Jorge (44a, público A, gerente geral), Amanda (29a, público B, caixa), Leandro (38a, público A, gerente geral), Patrícia (26a, privado $\mathrm{C}$, gerente de conta), Marta (26a, privado $\mathrm{D}$, caixa), Pedro (49a, público A, gerente geral), João (55a, público A, gerente geral), Carolina (47a, privado $\mathrm{D}$, gerente de conta), Vitória (26a, público A, auditora) e Cláudio (40a, público A, gerente geral) participaram de entrevistas individuais semiestruturadas, e pertenciam 
tanto aos bancos públicos $\mathrm{A}$ e $\mathrm{B}$, quanto aos bancos privados C e D. Já Mário (51a, público E), Paulo (34a, público E), Luiza (48a, público E), Robson (38a, público E), Maria (33a, público E), Miriam (40a, público A) e Roberta (46a, público A) participaram de grupos focais, e pertenciam aos bancos públicos $\mathrm{A}$ e $\mathrm{E}$.

A coleta de dados ocorreu por meio de dois grupos focais, com um total de 26 participantes, duração aproximada de 90 minutos cada um, realizados por ocasião de um encontro de bancários no Sindicato dos Bancários de Porto Alegre e Região. E por meio de 12 entrevistas individuais, com duração aproximada de 50 minutos cada uma, realizadas em locais da conveniência dos entrevistados. Ambos privilegiaram dimensões como modos de gestão do trabalho bancário, cotidiano do trabalho, e situações que exigiram decisões e escolhas pessoais no contexto do trabalho bancário com reflexos para a vida como um todo. Cabe ressaltar que não houve limitações ou peculiaridades quanto ao fato de os dados serem oriundos de entrevistas individuais ou de grupos focais. A opção pela realização de grupo focal se mostrou pertinente uma vez que a interação esperada entre os participantes se confirmou e possibilitou que comentários feitos por uns fossem legitimados por outros, ou que contribuíssem para lembrar fatos ou desencadear exemplificações.

Para a análise dos dados procedeu-se, sequencialmente, conforme orientações de Minayo (2001), a uma pré-análise do material, que permitiu a definição das unidades de sentido; e a uma exploração do material, com mapeamento dos temas emergentes. Esse procedimento de análise do conteúdo das entrevistas individuais e dos grupos focais possibilitou evidenciar, a partir do objetivo da pesquisa, categorias relativas à vivência de dilemas pessoais no trabalho imaterial bancário. São elas: medo da incompetência e estigma de perdedor, nomadismo involuntário, captura e dominação do tempo de vida, corrida individualizada para o mérito, medo da estagnação profissional, e saúde na precarização das relações de trabalho. Por último, procedeu-se a interpretação dos dados à luz da teoria. Cabe ressaltar que a análise e interpretação dos dados provenientes das entrevistas individuais e dos grupos focais priorizou o entendimento qualitativo da realidade social à luz da literatura pertinente, em especial os estudos de Bauman (2001, 2007a, 2007b), Sennett (2001, 2006) e Gaulejac (2007).

\section{Apresentação e análise dos resultados}

\section{Dilemas relativos ao medo da incompetência e ao estigma de perdedor}

A exemplo do constatado em outra pesquisa (Grisci \& Bessi, 2004), os motivos que impulsionam os sujeitos à construção de uma carreira bancária se viram abalados perante as transformações do trabalho que desencadearam tensão e sofrimento. Verificou-se, entre aqueles mais velhos e com carreira ascendente, que a trajetória profissional podia ser experimentada desde uma posição de status que os colocava em evidência frente à comunidade. No que diz respeito às vendas $\mathrm{e}$ às metas, recordam: "a gente vendia porque gostava de vender" (Luíza). Entretanto, se antigamente o "banco era uma ilha rodeada de clientes" (Mário), atualmente tal situação se inverte, pois "agora o cliente é uma ilha rodeada de bancos por todos os lados" (Mário). Nessa perspectiva, mostrou-se imprescindível àqueles que almejassem ascender profissionalmente adaptar-se ao novo projeto organizacional respondendo às exigências de novos conhecimentos, modos de ser e agir frente a um ritmo de trabalho tomado pela velocidade.

Diante disso, "os mais antigos, não preparados para viver no mundo tecnológico de hoje" (João) se flexibilizaram frente às novas exigências que trouxeram consigo uma mudança na percepção que o sujeito tem de si. Afirmam "eu tinha outra visão da profissão, do bancário. A gente teve uma transformação violenta a cada dia e tem que ir se adaptando ao processo. ... Tem que ser resiliente" (Pedro). Sabe-se que a disposição por adaptação coloca o trabalhador em um constante estado de alerta, de hiperativismo conforme sugerido por Gaulejac (2007), podendo tornar-se fonte de sofrimento psíquico devido ao medo da incompetência, como apontado por Dejours (2001).

A ideia de precarização do trabalho bancário ao longo de suas reestruturações se explicita na observação "hoje as pessoas chegam aqui, te enchem de desaforo e vão embora" (João), e colabora para o fato de, mais recentemente, a entrada no banco se dar, principalmente, por força de necessidade, pois "nunca tive vontade de ser bancária, não foi nenhum sonho de criança trabalhar com isso" (Marta). Nesse sentido, verifica-se, hoje, que o trabalho tem se resumido, aos olhos dos bancários, a um meio de sustento cada vez mais desvinculado àquela posição de status anteriormente experimentada. Tal constatação sugere a existência de um dilema pessoal que se constrói na comparação por contraste entre o atual e o antigo, no dar-se conta de que sua decisão pregressa conduziu-o a viver uma vida ao mesmo tempo considerada não satisfatória, mas também não mais passível de abandono ou de reconstituição.

O estado de tensão e angústia, que aflige o sujeito, extrapola a esfera do profissional e toma o convívio familiar e social. Cláudio expôs isso ao relatar uma discussão considerada intensa que teve com a esposa, o que lhes acarretou sofrimento psíquico. Ele, aos 40 anos de vida e quase 20 anos de banco, pensa que, em optando por mudar de trabalho, teria que fazê-lo imediatamente. 
Diante disso, se vê "em uma encruzilhada", o que para ele se revela como um questionamento: "é hora de mudar?" "É um baita dilema", ele diz, contrariando o fato de que nem sempre um dilema se mostra configurado como tal para os sujeitos que o vivenciam. Para Bauman (2007a, p. 8), essas angústias ocorrem porque "prever tendências futuras a partir de eventos passados torna-se cada dia mais arriscado e, frequentemente enganoso".

A partir do momento em que o sustento próprio e de outros é o principal fator que prende o sujeito ao trabalho - "o bancário é muito mal acostumado porque reclama, mas tem beneficios e tu acabas indo, levando" (Patrícia) - estratégias de enfrentamento são criadas no sentido de tornar a rotina mais suportável. Racionalizações sobre o trabalho levam o sujeito a aderir ao ideal da instituição, de modo que os modelos de valores das empresas se tornam também modelos de valores do sujeito (Gaulejac, 2007). Nesse sentido dizem " $a$ gente carrega uma bagagem de valores e quando chega à empresa tem que substitui-los pelos valores da empresa" (Maria). Da observância de muitos de que, por vezes, não há como encontrar um ponto em comum entre os valores pessoais e os da empresa, identifica-se um dilema: ou o sujeito cumpre as solicitações para manter-se incluído no trabalho e perde a paz de espírito; ou preserva a paz de espírito e arrisca-se a ser excluído do trabalho. Qualquer escolha que faça o coloca na posição de perdedor. Corrobora isso a percepção de Luíza, de que se o banco "tiver que escolher entre um bom funcionário mau vendedor e um mau funcionário bom vendedor, com certeza o mau funcionário vai ser escolhido" (Luíza); e "não interessa se tu atendes bem, se ganhas elogio do cliente, tem que mostrar um número, e isso é mês a mês" (Patrícia). A existência de um descompasso entre os critérios de avaliação da empresa e o que seria justo aos olhos dos sujeitos propicia o que Gaulejac (2007) aponta como uma crise de simbolização; e condiz com as observações de Sennett (2001, p.21) de que as "qualidades do bom trabalho não são as mesmas do bom caráter".

Conforme ascende na carreira, o sujeito enfrenta situações que antes desconsiderava ou julgava não existir. Afirmações como "eu achava fácil, talvez por não estar na função. Mas não é, é bem complicado" (Patrícia) apontam que a passagem de uma posição de nível operacional para uma posição de nível gerencial é experimentada como um divisor de águas para a carreira. O próprio fato de substituírem colegas por alguns dias já se revela como uma experiência capaz de colocar o sujeito diante de dilemas requerentes de resolução na perspectiva do "aqui e agora" e no ritmo de trabalho da organização. Amanda lembrou como isso a afetou:

aquilo mexeu comigo, eu lembro como se fosse ontem. Falei que a gente tem que começar a deixar de ter pena de quem está sentado na nossa frente e vamos ter que começar a pensar que o cliente não tem pena do nosso bolso. Doeu-me dizer isso.

Nesse sentido e, de acordo com Gaulejac (2007), aquele que assume a gerência é colocado frente a dilemas advindos de sua posição de intermédio entre funcionários e direção. A posição ocupada na estrutura organizacional imputa ao sujeito reproduzir aos demais o discurso gerencial em prol do projeto organizacional, mesmo que tal discurso se mostre descolado de si. Contribui para isso a percepção de encontrar-se subjugado às instabilidades do trabalho, afinal entendem que "eu estou gerente, não sou gerente" (Leandro), o que foi referido também por sujeitos de outros estudos (Grisci, Chemale, Hofmeister, \& Becker, 2006).

\section{Dilemas relativos ao nomadismo involuntário}

Em relação ao processo de ascensão profissional, hoje, ele requer que os sujeitos estejam dispostos a deixar seu lugar a qualquer momento, aceitando oportunidades assim que estas apareçam, mesmo que, de fato, não sejam oportunidades. A imagem do profissional fracassado não se restringe apenas ao mau vendedor, mas, principalmente, àquele colega que não buscou os meios para a ascensão e se encontra - como disseram acomodado há muito tempo no mesmo cargo. Quem já está em postos de maior responsabilidade e "assumiu o risco" (João), menciona "os nossos caixas, a maioria está ali e por mais que a gente tente incentivar, eles ficam na deles. ... eu diria que eles são os acomodados ... fica mortinho ali, não faz nada, não pensa nada, não é nada" (Pedro). Aos que não se disponibilizam a se mover rapidamente e perdem tais oportunidades, restaria culpa pela estagnação profissional (Bauman, 2001), pois "nessa dinâmica da sobrevivência as pessoas pagam o preço das oportunidades ... hoje, se o cara estiver numa cidade e quiser ficar lá, está morto" (Ronaldo). Coincidentemente, nas palavras de Sennett (2001, p. 102) lê-se que "não se mexer é tomado como sinal de fracasso, parecendo a estabilidade quase uma morte em vida". À ideia de imobilidade associa-se a de morte, a de tornar-se um nada, que impele o sujeito ao nomadismo involuntário e suas consequências humanas, já apontadas por Grisci, Chemale, Hofmeister e Becker (2006).

Diante da possibilidade de ser julgado como o acomodado, o estagnado, o "mortinho", o sujeito vivencia o dilema de aceitar os desafios de uma ascensão, por vezes prematura e, concomitantemente, conviver com a ideia e o medo da incompetência; ou resignar-se ao fato de que não tem o perfil para a função e ficar subjugado aos comentários de colegas. Sendo assim, a racionalização sobre o processo de ascensão e a autocobrança surgem como modos de enfrentamento do dilema: 
tem lados positivos e negativos ... O lado positivo é que, querendo ou não, eu sou nova e já consigo ser gerente, é um reconhecimento. O lado negativo é do peso da responsabilidade. Perdi minha saúde porque sou uma pessoa completamente $100 \%$ cobrança, então eu me pergunto se tenho ou não perfil para trabalhar nisso. (Patrícia)

De acordo com Bauman (2007a), ao sujeito visto como 'free-chooser'é cobrada a resolução de dilemas advindos de circunstâncias instáveis. Por vezes, as circunstâncias estão fora do alcance de sua compreensão e capacidade de ação. Além disso, a busca pelos melhores lugares implica a convivência em um ambiente propício à competição e deste modo, racionalizam a respeito do preço que pagam pela possibilidade de estar entre os bem sucedidos. Sobre isso, Leandro pondera que "para se dedicar a algo, tem que abdicar alguma coisa; não tem como ser bom em tudo."

\section{Dilemas relativos à captura e dominação do tempo de vida}

Para aqueles que ocupam posições de nível operacional, configuram-se dilemas oriundos da pressão pelo atingimento das metas e da organização do tempo de trabalho e de não trabalho, pois "o meu tempo não é meu, é do banco. Eu tenho que estar disponível sempre. Dá impressão que eu não tenho vida própria" (Marta). Tal constatação remete à rotina de uma vida líquida, que leva à desorientação e deixa o indivíduo sob constante falta de itinerário e direção.

Saber orientar-se dentro dessas perspectivas de incertezas e instabilidades demanda que os sujeitos busquem modos de enfrentamento de dilemas capazes de rapidamente promover o alívio sobre as tensões que algumas situações podem trazer, pois "quando acontece algo a gente acha que é o fim do mundo, mas na outra semana já está tudo bem de novo. O trabalho não para" (Jorge). Nesse sentido, observa-se que o sujeito molda-se à dinâmica de uma vida líquida que se baseia em uma narrativa descrita como uma série de reinícios (Bauman, 2007b).

De modo geral, no que diz respeito às metas, os dilemas afloram exacerbados, pois afetam diretamente nos resultados da empresa sendo, portanto, de interesse de todos, inclusive dos colegas, pois as avaliações de desempenho os tomam individual e coletivamente. Dessa forma, o dilema se origina de constatações como esta: "se eu fiz débito automático naquele mês, no mês seguinte a pessoa não vai mais aparecer para pagar a conta, ou seja, a meta aumenta, mas a possibilidade [de venda de produtos] diminui" (Marta). O enfretamento de tal dilema corrobora com uma exaustiva busca de reconhecimento do trabalho realizado, afinal "quando os critérios de sucesso se tornam cada vez mais exigentes e os riscos de fracasso cada vez mais presentes"
(Gaulejac, 2007, p. 227), o sujeito se vê compelido a prejudicar-se para alcançar objetivos estabelecidos pela empresa. Frente a isso, entendem que "a medição é essa: quanto mais tu atinges as metas, mais tu és cobrado ... Tem que ser a bola da vez o tempo todo, e isso reflete na tua vida pessoal" (Roberta). Trata-se de um dilema que se dinamiza na relação com o tempo: privilegiar o aqui e agora em termos de alcance das metas e diminuir as possibilidades futuras, ou fragilizar o aqui e agora em termos de alcance das metas e aumentar as possibilidades futuras. Em geral a opção é pelo aqui e agora, mas postergar a ansiedade e o sofrimento não é sinônimo de sua inexistência.

\section{Dilemas relativos à corrida individualizada para o mérito}

De acordo com as práticas gerencialistas, ao mesmo tempo em que se demanda cooperação, impõe-se uma corrida individualizada para o mérito (Gaulejac, 2007). Neste sentido, o sujeito "tem uma meta individual e tem uma meta de grupo, tem que cumprir as duas. Mas como é que tu vais fazer isso? Se tu ajudas o grupo, tu és criticado, se tu fazes individualmente, tu não prestas" (Roberta). Essa contradição se reflete em surgimento de dilemas, pois "se tu fores honesto com a necessidade do cliente, se tu fores honesto com a necessidade da empresa, se tu fores honesto com a tua necessidade pessoal e profissional, tu não chegas a lugar nenhum, porque é um conflito constante" (Roberta). Tais afirmações contrapõem a existência de uma lógica que diz respeito ao trabalho em equipe onde "cada um ajuda o outro, buscando o bem comum" (João). A ideia de que o ambiente de trabalho privilegia a lógica do "é cada um por si. É a sobrevivência" (Amanda) existe e é fonte de dilemas.

Destarte, o indivíduo se vê entre a sua ética pessoal e a ética gerencial, que parecem se afastarem entre si, de modo que, na visão de muitos sujeitos,

muita gente acaba sendo lesada por ser ético demais. Às vezes o bancário não pode ser muito ético, apesar de ter muitas leis que exigem a ética. A gente estuda, tem uma certificação, um livro inteiro só de ética. Ai tu te perguntas: ser ético ou atingir as metas? (Patrícia)

Frente a esse dilema, optam pelo discurso a favor do interesse do capital, levando o sujeito a cobrir com intenções louváveis certas práticas que antes assim não julgariam (Gaulejac, 2007). Tal discurso se apresenta, por exemplo, no argumento de venda, pois "se tu não oferecer, não colocar pro cliente os produtos que temos pra ele comprar e, muitas vezes, forçar ele a enxergar o produto como uma oportunidade de negócio e de ganho, o cliente não compra" (João), ao mesmo tempo em que "você tem que achar um equilibrio entre as normas, mas também não deixar de fazer negócios" (Jorge). Para não 
se verem paralisados, os sujeitos fazem suas escolhas, solitariamente, por vezes sem tempo e sem condições de reflexão, no sentido de que a gestão gerencialista se mantenha vigente. A lógica do up or out expressa por Gaulejac (2007) impele à superação em favor do sistema, a fim de garantir a inclusão no mercado de trabalho.

$\mathrm{O}$ receio do estigma de perdedor leva os sujeitos a desenvolverem entre si uma relação ambígua que os coloca ora como amigos e engajados na equipe, ora como rivais em potencial. A ambiguidade leva a comentários que perpassam desde a manutenção de um discurso gerencial que racionaliza esta ambiguidade, até a externalização de como se dá esta dinâmica:

se você dá uma dica para a melhoria de trabalho no grupo, o colega que tem uma visão individual te chama de bobo, porque tu deverias ter guardado isso pra ti. Se o resultado é imediato, porque tu vais dar para o grupo? (Roberta)

Sendo assim, "as pessoas têm a informação, mas elas não passam" (Amanda). Diante disso, especula-se a existência de um dilema pessoal negado, não passível de identificação, relativo à própria imagem que o sujeito constrói de si, condizente com a corrosão do caráter amplamente discutida por Sennett (2001).

Nesse sentido, a busca pelas melhores posições dentro da empresa deve respeitar critérios formais e que visam atender a todos igualitariamente. Contudo, não deixaram de ressaltar que a capacidade de relacionamento e a construção de redes de contato são fundamentais para a ascensão, numa perspectiva instrumental. Destacam que "o banco tem todo um sistema de pontuação e tal, mas tem como burlar. Se alguém te quiser em um cargo, te coloca" (Amanda).

Compreender o modo de construção das redes de contato e da busca pelo reconhecimento, pode se constituir como fonte de sofrimento psíquico, pois o sentimento de impotência frente ao que os sujeitos chamam de desilusões do trabalho revela que "existe a ilusão de que você faz o seu caminho, mas não é bem assim. Às vezes a coisa pára e tu não tens força para seguir adiante" (Marta). Constata-se que na sociedade gerencialista se demanda que cada sujeito sinta necessidade de rentabilizar-se e avaliar seu próprio desempenho, conforme já anunciava Gaulejac (2007). Portanto, ao ser convidado a realizar o balanço sobre si mesmo e seu desempenho, o sujeito é confrontado com essas desilusões, restando, muitas vezes, a resignação diante de fatos que estão fora do seu controle.

Ainda em relação à corrida individualizada para o mérito, há contradição entre o preparo formal e acadêmico exigido ao sujeito e o que de fato lhe é possível realizar, pois a própria mobilidade - ou nomadismo involuntário - a qual estão expostos faz com que não consigam obter a formação necessária dentro do tempo esperado. Sobre isso, argumenta um dos sujeitos: "fazer uma faculdade é uma dificuldade, porque o banco te cobra demais. E os funcionários que não tem isso vão ficando meio que de lado" (Pedro). Sendo assim, rentabilizar seu tempo e seu trabalho, são as formas utilizadas para aqueles que não querem ser enquadrados no grupo dos perdedores.

Desprovidos de crítica frente ao dilema entre ser tomado pela eminência de ser compreendido como " $u m$ nada" (Pedro) e "um morto" (Ronaldo) ou pertencer ao grupo dos vencedores - que não necessariamente reflete seus valores - o sujeito recorre ao vale tudo para ascender, mesmo que seja em detrimento a sua ética, pois

é automático. A gente tem que vender empréstimo para aposentado e, conforme a pessoa vai usando, a linha de crédito vai aumentando. É um túnel sem saída. Eu vejo que a pessoa fica feliz, fica deslumbrada e tem que instigar ela a usar o crédito. (Marta)

Além disso, possibilitam compreender essa situação como um dilema a ser superado pela categoria, pois entendem que a construção do profissional bancário de sucesso depende, exatamente, da capacidade individual de colocar em segundo plano certos julgamentos éticos em relação às metas e às vendas, por exemplo. Miriam e Amanda sintetizam esse dilema ao questionarem, respectivamente, "as pessoas que empurram coisas que o cliente não precisa estão tendo moral? Estão sendo éticas? Estão sendo justas? É essa a questão".

Tem momentos que o meu discernimento e a minha opinião das coisas não querem dizer nada. Ai entra a questão pra ti ser vencedor ou perdedor. Tu tem que saber conviver com isso. Tem que ter noção de que penso dessa forma, mas trabalho em uma instituição financeira e não de caridade. Tem que ser frio.

Em um ambiente de trabalho onde as pessoas entendem a competição como fator de produtividade, a ética é construída dentro de uma lógica que privilegia o individualismo. O simples atingimento das metas não se constitui como fator primordial para o reconhecimento do bancário. A lógica de trabalho impõe a necessidade de que todas as metas sejam extrapoladas, de modo que isso sim será o fator do reconhecimento. Dessa forma, a individualização do trabalho acirra-se ainda mais, como ressalta Marta:

o importante, além de vender, é extrapolar a meta, porque é assim que você vai mostrar que é produtiva e vai poder sair daquele cargo. Felizmente, eu aprendi. Eu faço a mais e se o colega não fez... Eu já me vendi ao sistema e aprendi que não vou passar pra ele.

Entre aqueles em cargo de gerência, aplica-se a mesma lógica, contudo apresentam sua avaliação a partir de um discurso mais cauteloso que somente vem a reforçar a instalação de dilemas: "aqui tem uma característica 
de o pessoal trabalhar de forma coletiva, ainda que tenha que priorizar a sua carteira individual (Leandro).

Mostra-se clara a existência de uma diferenciação de discursos entre gerentes e funcionários de cargos operacionais a respeito das metas estabelecidas. Os primeiros mantiveram-se cautelosos e preferiram um discurso na ordem do politicamente correto, no sentido de apontarem as metas como uma ferramenta justa e indispensável para o tipo de trabalho que realizam. Já os segundos não esconderam certas insatisfações. Se para os gestores prevalece a ideia de que "se nós chegamos a 100\% da meta, não me interessa quem fez, tem que se ajudar" (Cláudio), para os demais se destaca que "na última vez que fui à agência tinha uma folhinha com o nome dos funcionários e o que cada um tinha vendido, para todo mundo olhar" (Amanda).

\section{Dilemas relativos ao medo da estagnação profissional}

Em razão da responsabilidade sobre as consequências do trabalho que realiza, o sujeito tem no medo mais um fator a administrar. Bauman (2007a) ressalta que o medo estimula reações defensivas e, portanto, propicia o surgimento de estratégias de defesa. Conforme diz um dos sujeitos, o medo

sempre está em foco, isso sempre existe. É imposto pelas chefias para você estar sempre preocupado com mais e mais. É a competição. Se você não quiser, vai para a rua. Eles põem essa pimenta pra ver se você está ligado... Eu uso como impulso. (Pedro)

Assim, promover o medo assume o sentido de uma estratégia gerencialista a fim de estimular o aumento de resultados lucrativos. Dentre os gerentes, por exemplo, aqueles que não correspondem às expectativas e sucumbem às pressões, podem ser colocados em agências menos expressivas, mas como lembra o Pedro, "se estiver no meio da carreira ele se abate demais e sai da função, é colocado em uma função diferenciada. São raros os que retomam a ascensão depois".

O medo da estagnação profissional constrói um ideal de carreira em que cada um compreende a necessidade de manter-se na 'vitrina', mesmo que para isso seus próprios valores devam ser 'revistos', já que "ou tu te ajusta e vende e mostra resultado para almejar algo melhor, ou tu segues teus valores e acaba fechando as portas, porque se tu não és o que vende mais, tu não estás na vitrina" (Paulo). A ideia de estar fora da vitrina associa-se à de tornar-se um nada, morrer.

A busca pelo reconhecimento se dá de forma contínua, mesmo que estejam cientes que este reconhecimento talvez nunca chegue, pois

tu vais te dar conta depois. Tu sempre fazes, mas o banco nunca vai estar satisfeito. Sempre vai dar um jeito de criar mais uma meta, mais uma campanha. Então é uma forma de não reconhecimento. Tu ganhou o teu salário por ter feito muito mais do que podia e no mês que vem vai ter que fazer de novo. (Patrícia)

Tal relato ilustra a prática condizente com uma cultura que busca promover continuamente novas demandas e maiores desafios; que incentiva a autocobrança e, portanto, amplia a sensação de dívida do sujeito frente ao seu trabalho, como apontam Tanure, Carvalho Neto e Andrade (2007).

Buscando diminuir a sensação de dívida, o bancário, por vezes, se vê obrigado a comprar os produtos que vende, não apenas para atingir as metas estipuladas, mas para manter-se aceito pelo grupo, afinal "me passam uma meta que não é minha, eu tiro dinheiro da minha conta para bater essa meta. Porque eu sei que na hora da cobrança a agência é um time, um todo. Mas se eu não bato a meta, eu estou fora da equipe, entende?" (Marta).

Essa afirmação vem ao encontro da colocação de Gaulejac (2007) a respeito da estigmatização do perdedor e da corrida para o mérito, muitas vezes travestida de um empenho em equipe, mas que, na verdade, mostra-se como uma busca individual, porém com consequências que atingem o grupo como um todo.

No que tange à decisão pela aposentadoria, esta também se constitui como dilema relativo ao medo da estagnação profissional, haja vista que estar de fora da realidade até então vivida pode trazer um novo olhar sobre tudo o que se passou e, por vezes, esse novo olhar permite uma crítica que antes não era possível de ser alcançada. Um dos sujeitos encontra-se justamente no impasse dessa decisão, pois vive o dilema que consiste em sentir-se "em uma idade madura para o trabalho, em termos de relacionamento e conhecimento" (João), e a consciência de que o trabalho bancário assumiu um ritmo muito estressante que exige do bancário um nível de autocontrole capaz de prejudicar o sujeito. Sendo assim, o dilema que se instala advém da própria avaliação que o sujeito faz em relação à vida profissional. Sente-se amadurecido profissionalmente e capacitado para contribuir, mas não mais se enquadra dentro de um ritmo e perfil exigidos que privilegiem os mais jovens com base em suas possibilidades de velocidade de resposta. Destaca-se que esse dilema não é exclusivo daqueles em final de carreira, às portas da aposentadoria. Se para os mais experientes o ritmo se coloca como obstáculo, para os mais jovens e flexíveis, muitas vezes a falta de experiência é vista como empecilho para o trabalho.

\section{Dilemas relativos à saúde na precarização das relações de trabalho}

Trabalhar em um ambiente que expõe o sujeito constantemente a pressões e instabilidades pode acarre- 
tar graves consequências à saúde, conforme atestam os estudos de Merlo e Lápis (2007) e também se verificou na presente pesquisa. Relatos que dão conta de uma saúde fragilizada à medida que o tempo diminui e as pressões aumentam não foram raros entre os bancários.

Tive um infarto e quase fui. Esse estresse que a gente vive. Eu não fumo, não bebo, faço exercício, não tenho sobrepeso, não tenho colesterol alto. É essa pressão terrivel. ... Podia cuidar melhor, eu não aprendi isso. Se sair 20 minutos antes do meu horário previsto, tenho um sentimento de culpa. Acho que não aprendi isso ainda, muita gente não aprendeu, a gente acha que o banco, que o nosso trabalho é a razão da nossa existência. (Ronaldo)

Em relação à saúde, um sujeito com 28 anos de trabalho bancário avaliou como tratou sua saúde ao longo desses anos e como o banco influenciou nesse aspecto. Destacou que a construção da carreira visando à ascensão na empresa leva o bancário ao limite máximo e que isso o impossibilita de imaginar as consequências futuras. Contudo, a saúde acaba revelando, anos depois, o resultado da velocidade imposta pelo ritmo de trabalho. Ressalta o sujeito que "o nosso setor exige potência máxima e eu já comecei a verificar que tem algumas coisas desgastadas e que estou corrigindo via química. Mas agora é tarde, agora tem que baixar a velocidade" (Pedro).

Mesmo entre os mais jovens, em início de carreira, o peso de novas responsabilidades afeta a saúde e a vida pessoal como um todo. Patrícia confidenciou o quanto sua saúde se fragilizou a partir do momento em que percebeu que adaptou sua vida para assumir uma posição de maior responsabilidade e, como consequência, teve a saúde seriamente comprometida ao entrar em um processo de anorexia nervosa. Seu relato: "perdi parte da minha vida pessoal por causa da saúde que o banco me tirou". Tal constatação revela-se como consequência de um estilo de vida baseado na disponibilidade total para com o trabalho. Isso encontra suporte nas argumentações de Bauman (2007a, p.10): "cabe ao sujeito a prontidão em mudar repentinamente de táticas e de estilo, abandonar compromissos e lealdades sem arrependimento - e buscar oportunidades mais de acordo com sua disponibilidade atual do que com as próprias preferências". As consequências de tais exigências acabam sendo expostas, também, através do comprometimento da saúde e da fragilização dos corpos.

\section{Considerações finais}

Buscou-se, para esta pesquisa, destacar e analisar os dilemas pessoais vividos na lógica do trabalho imaterial bancário que não distingue tempo de trabalho e tempo de vida, uma vez que se apodera da completude da vida em prol da produção, conforme Lazzarato e Negri (2001).

As análises permitiram verificar-se que são fontes de dilemas para os bancários os modos de trabalhar e de gestão que exigem dos sujeitos a cooperação necessária à produção do imaterial, tanto quanto incentivam a individualização condizente com a sociedade líquido-moderna marcada pela fluidez e instabilidades; bem como a dominação do espaço e do tempo pessoal, sob a premissa que toma o fracasso como tabu. As fontes de dilemas para os bancários correspondem, portanto, aos estudos de Lazzarato e Negri (2001), Bauman (2007b), Gaulejac (2007) e Sennett (2001).

Os dilemas que afloraram no cotidiano do trabalho imaterial bancário dizem respeito ao medo da incompetência e ao estigma de perdedor, ao nomadismo involuntário, à captura e dominação do tempo de vida, à corrida individualizada para o mérito, ao medo da estagnação profissional, e à saúde na precarização das relações de trabalho. Cabe ressaltar que, ainda que tenham sido apresentados separadamente, eles não só coexistem, mas também se entrecruzam e se intensificam uns nos outros. Embora nem sempre os dilemas se mostrem aos sujeitos configurados como tal, sua natureza, intensidade ou força não permitem ignorar as elaborações que Bauman (2007a, 2007b), Sennett (2001, 2006) e Gaulejac (2007) tecem acerca das incertezas e inseguranças que caracterizam a vida contemporânea.

A vivência de dilemas pessoais, no que diz respeito ao trabalho imaterial bancário, pode ser constatada em todos os sujeitos da pesquisa, e sobre eles se abateram as consequências advindas de suas escolhas, como já constatara Bauman (2007a). Nesse sentido, constatou-se que a responsabilidade de resolução dos dilemas vividos sempre é tomada numa perspectiva pessoal, independentemente de a eles se juntarem outros colegas ou até mesmo clientes. Desencadeados e visibilizados a partir das demandas do trabalho imaterial, os dilemas impõem aos sujeitos escolhas que, em geral, os levam a preterir os relacionamentos pessoais tanto no âmbito do coleguismo quanto no dos afetos em prol da rentabilização do trabalho.

A incumbência de atingir as metas estipuladas pelas práticas gerencialistas (Gaulejac, 2007), perpassou todos os dilemas que se evidenciaram ante o trabalho imaterial bancário. Apesar da manutenção de um prudente discurso a respeito das metas por parte daqueles em posição gerencial, os demais bancários as apresentaram em sentido divergente. $\mathrm{Na}$ pressão dos colegas, consciência de que somente extrapolando as metas é que se dá a ascensão profissional, instala-se uma relação ambígua de parceria e rivalidade que culmina na corrida individualizada para o mérito, e coloca à prova valores que o sujeito até então julgava inquestionáveis. 
A utilização das expressões "acomodado" e "mortinho" para referir àqueles que não pretendem assumir e/ou não buscam as melhores posições dentro do banco denota como se produz o estigma dos menos ambiciosos em relação às oportunidades ou aos desafios que o banco oferece. O estigma, portanto, é o reflexo do que se demanda ao sujeito na atual sociedade líquido-moderna, onde ficar parado significa excluir-se e estar à margem do que se espera e se entende por sucesso.

Destaca-se que a vivência de dilemas pessoais no trabalho imaterial bancário mostrou-se instigante e relevante objeto de estudo. Para futuras pesquisas sugere-se a ampliação para outras categorias profissionais, ou ainda, a realização de pesquisas com bancários a fim de observar como a vivência de dilemas pessoais se configura a partir de possíveis modificações nos modos de gestão, e dos efeitos da passagem do tempo cronológico.

\section{Nota}

1 A respeito das alterações da concepção e percepção do tempo e como tais alterações afetam os valores individuais e os processos sociais, ver também Harvey (1993).

\section{Referências}

Bauman, Z. (2001). Modernidade líquida. Rio de Janeiro: Jorge Zahar Ed.

Bauman, Z. (2007a). Tempos Líquidos. Rio de Janeiro: Jorge Zahar Ed.

Bauman, Z. (2007b). Vida líquida. Rio de Janeiro: Jorge Zahar Ed.

Dejours, C. (2001). A banalização da injustiça social. Rio de Janeiro: Editora FGV.

Gaulejac, V. (2007). Gestão como doença social: ideologia, poder gerencialista e fragmentação social. São Paulo: Idéias e Letras. Grisci, C. L. I. (2006). Trabalho imaterial. In A. D. Cattani \& L. Holzman (Orgs.), Dicionário de trabalho e tecnologia (pp. 327-329). Porto Alegre: Ed. UFRGS.

Grisci, C. L. I. (2008). Trabalho imaterial, controle rizomático e subjetividade no novo paradigma tecnológico. $R A E-$ eletrônica, 7(1), art. 4. Acesso em 02 de dezembro, 2010, em http://rae.fgv.br/sites/rae.fgv.br/files/artigos/10.1590_S167656482008000100005.pdf

Grisci, C. L. I. \& Bessi, V. G. (2004, julho/dezembro). Modos de trabalhar e de ser na reestruturação bancária. Sociologias, ano $6,12,160-200$.

Grisci, C. L. I., Chemale, G. C, Hofmeister, P. M., \& Becker, J. L. (2006, janeiro/março). Nomadismo involuntário na reestruturação produtiva do trabalho bancário. Revista de Administração de Empresas - ERA, 46(1), 27-40.

Harvey, D. (1993). Condição pós-moderna: uma pesquisa sobre as origens da mudança social ( $2^{\mathrm{a}}$ ed.). São Paulo: Loyola.

Lazzarato, M. \& Negri, A. (2001). Trabalho imaterial: formas de vida e produção de subjetividade. Rio de Janeiro: DP\&A.

Merlo, A. C. \& Lapis, N. L. (2007, janeiro/abril). A saúde e os processos de trabalho no capitalismo: reflexões na interface da psicodinâmica do trabalho e da sociologia do trabalho. Psicologia \& Sociedade, 19(1), 61-68.

Minayo, M.C. (Org.). (2001). Pesquisa social: teoria, método e criatividade (18 ed.). Petrópolis, RJ: Vozes.

Pelbart, P. (2000). A vertigem por um fio: politicas da subjetividade contemporânea. São Paulo: Iluminuras/FAPESP.

Sennett, R. (2001). A corrosão do caráter: conseqüências pessoais do trabalho no novo capitalismo. Rio de Janeiro: Record.

Sennett, R. (2006). A cultura no novo capitalismo. Rio de Janeiro: Record.

Tanure, B., Neto, A. C., \& Andrade, J. (2007). Executivos: sucesso e (in)felicidade. Rio de Janeiro: Elsevier.

Vergara, S. C. (2000). Projetos e relatórios de pesquisa em administração. São Paulo: Atlas.

Virilio, P. (1999). A bomba informática. São Paulo: Estação Liberdade.

Recebido em: 24/12/2009

Revisão em: 25/03/2010

Aceite final em: 28/03/2010

Carmem Ligia Iochins Grisci é Doutora em Psicologia pela PUCRS, possui pós-doutorado pela Universidade Técnica de Lisboa. Professora Associada do PPGA/EA/ UFRGS. Pesquisadora CNPq -1D. Endereço: Escola de Administração da UFRGS. Rua Washington Luiz, 855, sala 424. Porto Alegre/RS, Brasil. CEP 90010-460. Email: cligrisci@ea.ufrgs.br

Priscila Daniel Scalco é Bacharel em Administração pela UFRGS, Mestranda pela Universidade de Londres.

Gabriela Elnecave Kruter é Graduanda em Administração de Empresas pela UFRGS, bolsista de iniciação de pesquisa/CNPq.

\section{Como citar:}

Grisci, C. L. I., Scalco, P. D., \& Kruter, G. E. (2011). Dilemas pessoais no trabalho imaterial bancário. Psicologia $\&$ Sociedade, 23(3), 564-573. 